\title{
A Crise da Democracia Brasileira e os Rumos da Participação Institucional
}

\author{
Ana Paula G. Palacio*, Luciana F. Tatagiba.
}

\section{Resumo}

O objetivo desta iniciação, inserida em uma agenda mais ampla de pesquisa do NEPAC (Núcleo de Pesquisa em Participação, Movimentos Sociais e Ação Coletiva), foi uma análise da produção de conhecimento sobre as instituições participativas no contexto pós-impeachment. Para isto, foram construídos dois bancos de dados, que documentaram a produção online de Conselhos Nacionais de políticas públicas, blogs a eles atrelados, mídias alternativas e artigos acadêmicos publicados entre janeiro de 2015 e abril de 2019. Ao final, foi feita uma análise crítica mais ampla que permitiu avaliar o contexto do governo atual como um fechamento dos canais de acesso participativos institucionais.

\section{Palavras-chave:}

\section{Participação; democracia; instituições}

\section{Introdução}

Esta iniciação se insere em uma agenda mais ampla de pesquisa do NEPAC (Núcleo de Pesquisa em Participação, Movimentos Sociais e Ação Coletiva) acerca da trajetória da democracia no Brasil, e tem como objetivo principal a produção de conhecimento sobre as instituições participativas no contexto pós-impeachment. Para isso, foi realizada a construção de dois bancos de dados que buscaram sistematizar a produção acadêmica e também midiática com enfoque específico nos Conselhos Nacionais de políticas públicas.

\section{Resultados e Discussão}

Visando a revisão bibliográfica realizada da produção acadêmica feita entre 2015 e 2018 pelos grupos de pesquisa brasileiros atuantes na área de movimentos sociais, é possível perceber certa confluência de diálogos. Há certo otimismo sobre o contexto de produção, avaliado como de abertura política e ampliação do acesso aos canais institucionais de produção de políticas públicas. Os Conselhos Nacionais, apesar de suas limitações, podem ser vistos como vias democráticas resultantes disto. $\mathrm{O}$ questionamento a se colocar é sobre de que maneira é possível aferir estes mecanismos no contexto do atual governo, que caracterizou um fechamento dos canais de participação, que resvalou nos Conselhos, culminando até mesmo na extinção de alguns deles ${ }^{1}$. Os dados captados das mídias alternativas, entre novembro de 2018 e abril de 2019 permitem perceber que há pouca produção sobre os Conselhos, o que pode ser visto, também, como consequência do fechamento à participação por parte do contexto político atual.

O banco de dados das publicações dos Conselhos, blogs, e dos artigos produzidos pelos núcleos de pesquisa está disponível em: <https://bit.ly/2HaSEol> (acesso em: 05/07/2019)

E o banco de dados das publicações de mídias sociais está disponível em: < https://bit.ly/2XoWllu > (acesso em: 05/07/2019).

\section{Conclusão}

Desde o impeachment da presidente Dilma Roussef, pode-se avaliar que 0 acesso da sociedade civil à produção de políticas públicas tem ficado cada vez mais difícil. Há uma desqualificação dos Conselhos por parte do governo federal, atrelado a um fechamento dos canais participativos, tanto da sociedade civil, quanto dos movimentos sociais, o que pode ter resvalado na sua abordagem em pulbicações nas mídias.

Com isto, fica possível concluir que o contexto político atual dificulta os encaixes institucionais/relações entre Estado e Sociedade, implicando na necessidade de realizar de novos esforços teóricos para compreender como avaliar a política contemporaneamente.

1ABERS, Rebecca Neaera; SILVA, Marcelo Kunrath; TATAGIBA, Luciana. MOVIMENTOS SOCIAIS E POLÍTICAS PÚBLICAS REPENSANDO ATORES E OPORTUNIDADES POLÍTICAS. Lua Nova, São Paulo, n. 105, p. 15-46, Sept. 2018 . Disponível em: $<$ http://www.scielo.br/scielo.php?script=sci arttext\&pid=S010264452018000300002\&lng=en\&nrm=iso $>$. Acesso em: 05/07/2019. 2LAVALLE, Adrian Gurza; CARLOS, Euzeneia; DOWBOR, Monika;

SZWAKO, José (orgs.). Movimentos sociais e institucionalização: políticas sociais, raça e gênero no Brasil pós-transição. Rio de Janeiro: Editora UERJ, 2018.

3MIGUEL, Luis Felipe. RESGATAR A PARTICIPAÇÃO: DEMOCRACIA PARTICIPATIVA E REPRESENTAÇÃO POLÍTICA NO DEBATE

CONTEMPORÂNEO. Lua Nova, São Paulo, n. 100, p. 83-118, Jan. 2017 . Disponível em: <http://www.scielo.br/scielo.php? script=sci_arttext\&pid=S0102-64452017000100083\&lng=en\&nrm=iso $>$. Acesso em: 05/07/2019. http://dx.doi.org/10.1590/0102-083118/100. 4TATAGIBA, Luciana; GALVAO, Andreia. Os protestos no Brasil em tempos de crise (2011-2016). Opin. Publica, Campinas, v. 25, n. 1, p. 63-96, Apr. 2019 . Disponível em: <http://www.scielo.br/scielo.php? script=sci_arttext\&pid=S0104-62762019000100063\&lng=en\&nrm=iso >. Acesso em: 05/07/2019. Epub Maio de 16, 2019. 